\title{
Factors Affecting the Preferences of Primigravida Women for Choosing a Public Hospital
}

\author{
Sedigheh Zalzar ${ }^{1}$, Khalil Alimohammadzadeh ${ }^{1, *}$ \\ ${ }^{1}$ Department of Health Services Management, Tehran North Branch, Islamic Azad University, Tehran, Iran \\ *Corresponding Author: Khalil Alimohammadzadeh, Assistant Professor, Health Services Management, Department of Health Services \\ Management, Tehran North Branch, Islamic Azad University, Tehran, Iran. Email: drkhalilalimohammadzadeh@gmail.com
}

\begin{abstract}
Introduction: Finding the factors affecting patients' tendency to a hospital, can improve the health system. The purpose of this study was to recognize the factors affecting primigravidas' preferences to select a public hospital, in order to determine the correlation on these preferences.

Methods: In this cross-sectional study, 220 primigravida women who had admitted for delivery or cesarean in the Kamali public hospital in Karaj were selected using random sampling in 2014. Data collected by semi-structured questionnaire were analyzed by using structural equation modeling method and Lisrel Software.

Results: Among the six studied indicators (services, processes, providers, cost, advertisements, and place), the most effective factor was the type of service (regression weight 0.89 ), and the lowest effective factor was services' cost (regression weight 0.64). Moreover, providers and services had the most correlation and processes and services cost had the least correlation.

Conclusion: The clients' requests must be considered to improve the quality and quantity of services and processes. Authorities should try to solve medical problems and provide medical facilities and welfare in hospitals in order to attract clients' confidence.

Keywords: Primigravida, Preferences, Hospitals
\end{abstract}

Article History: Received: 25 May. 2015; Accepted: 28 Jul. 2015; Online Published: 26 Nov. 2015

Cite this article as: Zalzar S, Alimohammadzadeh K. Factors affecting the preferences of primigravida women for choosing a public hospital. Int J Travel Med Glob Health. 2015;3(4):165-9.

\section{Introduction}

In Iran, the public sector, especially the Ministry of Health and Medical Education provides more health services compared to the private sector. It is said that about $70 \%$ of medical institutions are related to public medical university [1]. Turkey has created a system in which is giving funds to the public and private hospitals and considerable freedom to patients to choose their physician and hospital [2]. In the hospital, patients' preferences are one of the most important factors for making decisions about their cares and enhancing the quality of the patient-centered care [3]. The results of a study showed that pregnant women are encountered with two problems about their choice: 1 . Decision that is not based on knowledge and information, 2. lack of sufficient awareness leading to incorrect performances [4]. The main factors associated with choosing a hospital were medical services, accessibility, age, sex and education. Little importance was given to income and occupation [5]. Consultation with patients about their treatment had the highest relative importance (37.1\%) [6]. Patients with no formal qualifications and those living in urban centers were more likely to choose their local hospital, and patients with a bad or mixed past experience at their local hospital were more likely to choose an alternative [7]. Controlling for provider availability, hospital users were more likely to be rural residents, to have traveled away from their home countries for care [8]. Nowadays many patients can choose their primary care, hospital and provider in order to increase their participation in care [9]. Patients' choices are determined by a complex interaction between patient and provider characteristics. Patients take account of a variety of structural, process and outcome characteristics of providers, differing in the relative importance they attach to these characteristics [10]. The priority of mothers will be influenced by delivery agents and cultural issues to determine the type of delivery [11]. Good communication with physicians and other therapists have always been considered as the basis of service quality in the view of patients [12]. By awareness of hospitals' capacities, patients can choose their hospital more confidently [13]. The results showed that mothers were more satisfied of physical and comfortable aspects, but the informational aspects of care in both kinds of hospitals was low [14]. Both, low literacy and lower patient activation levels were negatively associated with active provider choice [15]. It can be said that $1 / 4$ patients preferred doctors GP or specialist to decide which hospital to choose. Patients with higher education, patients aged 25-65 years, and stable individual characteristics were more willing to use the information obtained from the Internet or the newspaper to make a decision [16]. Patient decisions for choosing a hospital are influenced by a prior use of health services in that hospital and patient-to-hospital distance [17]. Public reports can be considered as tools which managers can use to help patients differentiate among providers [18]. The results show that relative to self-pay patients, Government and Labor Health Insurance beneficiaries and high-income patients are more likely to use county hospitals, while patients covered by the rural Cooperative Medical System (CMS) are more likely to use village-level facilities. The results also reveal that disease patterns have a significant impact on patient choice of provider [19].

\section{Methods}

This descriptive cross-sectional study was conducted among 220 primigravida women admitted for delivery or cesarean in a public (Kamali) hospital in Karaj during the fourth quarter of 2014. By using the sampling method, 200 women completed the questionnaires. At first, all the participants were given explanations about the research project and then their oral consent was obtained and finally, researchers designed a questionnaire based on previous

International Journal of Travel Medicine and Global Health 2015; 3(4): 165-169. 
studies and were completed by patients. The first part of questionnaire consists of demographic and admitted information and the second part consists of standard quantitative questions (five options Likert's scale) related to the causes and factors affecting on choosing a hospital (Table 1). In order to determine the content validity of the test, 5 experts with research experiences in the field were used. Data were analyzed by using the structural equation modeling method and Lisrel Software.

\begin{tabular}{lccc}
\multicolumn{4}{c}{ Table 1. Study's dimensions and scales in the distributed questionnaire } \\
\hline Series & $\begin{array}{c}\text { (Study's } \\
\text { variables)Dimensions }\end{array}$ & $\begin{array}{c}\text { The number of } \\
\text { variables }\end{array}$ & Questions \\
\hline 1 & type of service & 6 & $1-6$ \\
2 & processes & 5 & $7-11$ \\
3 & providers & 7 & $12-18$ \\
4 & cost & 4 & $19-22$ \\
5 & advertisement & 4 & $23-26$ \\
6 & place & 6 & $27-32$ \\
7 & Sum of variables & 32 & 32 \\
\hline
\end{tabular}

\section{Results}

In this study on 220 nulliparous in a public hospital, the findings consist of $14 \%$ under the age of 20 years, $68.5 \%$ about 20 to 30 years, $17.5 \%$ over the age of 30 years , $36 \%$ under school diploma, $42.5 \%$ diploma, $21.5 \%$ over diploma, $91.5 \%$ were urban people and $7.5 \%$ were rural people, $4.5 \%$ were employees, and $89.5 \%$ were housekeeping, $25.5 \%$ earn less than $500000,60.5 \%$ earn from 500000 to one million, $13.5 \%$ earn between one and two million, $24.5 \%$ were owners, $61.5 \%$ were tenants, $58 \%$ had social insurance, $30.5 \%$ had Iranian health insurance, $48.5 \%$ had normal delivery and $51.5 \%$ had cesarean, in $34.5 \%$ of cases the length of stay was one day, $45 \%$ were two days, hospitalizations in $86.5 \%$ cases were the first time, $11 \%$ were the second time, only $2 \%$ of cases were referred to the hospital by the ambulance. In general, in this research, the type of admission of patients and the selection of a public hospital (in non-emergency cases), was influenced by their individual tendency, their physicians advices and others' recommendations.

In the final model, among six studies' variables, the most effective factor in choosing public hospitals was the type of service (regression weight 0.89), and the lowest effective factor was service costs (regression weight 0.64). The greatest correlation (0.77) was between the type of service and providers factors and the lowest correlation (0.49) was between cost and process factors. Among the six factors which included: type of service, processes, providers, costs, advertising and place factors, "the service" and " the providers " have the greatest impact on nulliparous women for choosing hospitals. This was while "the process" and "the cost" were the most common affecting indicators.

\section{Discussion}

In public hospitals, the most effective factors in choosing hospitals are the type of service (Regression weight 0.89), and the lowest effective factors are service costs (regression weight 0.64). Based on the type of service, preparing all kinds of expertise, has the highest impact (0.67) and the preparation of medicine and other medical supplies has the lowest impact (0.59). Based on the type of service, the most effective factor in choosing a hospital was preparing all kinds of expertise (0.67) and the lowest effective factors was the preparation of medicine and other medical supplies (0.59).
Based on the cost factor, the most effective factor in choosing a hospital was the patient's insurance coverage $(0.72)$ and the lowest effective factors were costs and other side costs (transportation, ...) (0. 43). Based on the process, the most effective factor in choosing a hospital was speed of services (0.83) and the lowest effective factor was delaying in admission and wasting time in other hospitals $(0.12)$. Based on the providers, the most effective factors in choosing a hospital was better care $(0.81)$ and responsibility about patients (0.77) and the lowest effective factors was appearance of providers (0.46). Based on the advertisement, the most effective factor in choosing a hospital was consultation with practitioners (0.66) and the lowest effective factor was an acquaintance employee in hospital (0.59). Based on the place, the most effective factor in choosing a hospital was cleaning (0.85) and the sign $(0.77)$ and the lowest effective factors were being in the center of the city (0.49), and better access (0.52)

The results of Varmaqhanie et al.'s study (2008), has mentioned that the lack of proper health insurance coverage acceptable in private hospitals is one of the most important factors affecting the choice of government hospitals. [1] The results of Ameri et al.'s study (2013) in regards to the cost point of view, advertisement and place items are confirmed by this study. It mentioned that the highest score belongs to the quality factor (an average 68.40) and the lowest score is related to economic factors (an average 41.40) The highest score of quality belongs to the relationship between the doctor and the patient (an average 81.50) and the lowest score of economic factors was related to costs of hospitals (51.12) [20]. The results of Tavana's study (2012), in regards to the cost and process point of view are confirmed by this study. It has been mentioned that all the indexes (access to services, complete package, quality of services, time and speed of service) were associated with the patients' tendency to choose hospitals except the cost index [21].

The results of Sidiki et al.'s study (1998) in regards to the cost and services point of view are confirmed by this study. It can be mentioned that the highest score belongs to the quality factor (reputation of the staff and hospital, having care and follow-up, high standards of equipment) and the lowest score is related to the cost factor [22].

The results of Lis et al.'s study (2011) in regards to the quality of services are confirmed by this study. Patients recommend choosing high quality hospital to others $(77 \%)$. It included acceptance rate, the timing of services and the direct involvement of the patient in treatment decisions [23].

According to AlrubraieeL, Alkanydya (2011), there was the positive impact the relationship between service quality and confidence that is confirmed by this study [24].

The results of Lux et al.'s study (2011) in regards to the quality of service point of view are confirmed by this study. On the other hand, the place point of view (access to hospital) isn't confirmed. Other mentioned factors are private doctors, family and friends' recommendations [25].

The results of Gowrisankaran et al.'s study (2011) in regards to the quality of services point of view are confirmed by this study. It has been mentioned that the reduction in services results in a $28 \%$ drop in admission rates [26].

The results of Birk et al.'s study (2012), in regards to the quality of services and place factors point of view are against the results of this study. It has been mentioned that the short distance to hospitals was one of the effective factors. Official information on quality and service (waiting time) at hospitals 
were at a very low degree [27].

According to Khayatan et al.'s study (2010), four factors (individual, geographic, financial and institutional) were effective. The results are confirmed by this study. It mentioned that several factors influence people's access to health care services at health centers including factors such as organizational structure, health service providers, transportation systems and the level of insurance coverage [28].

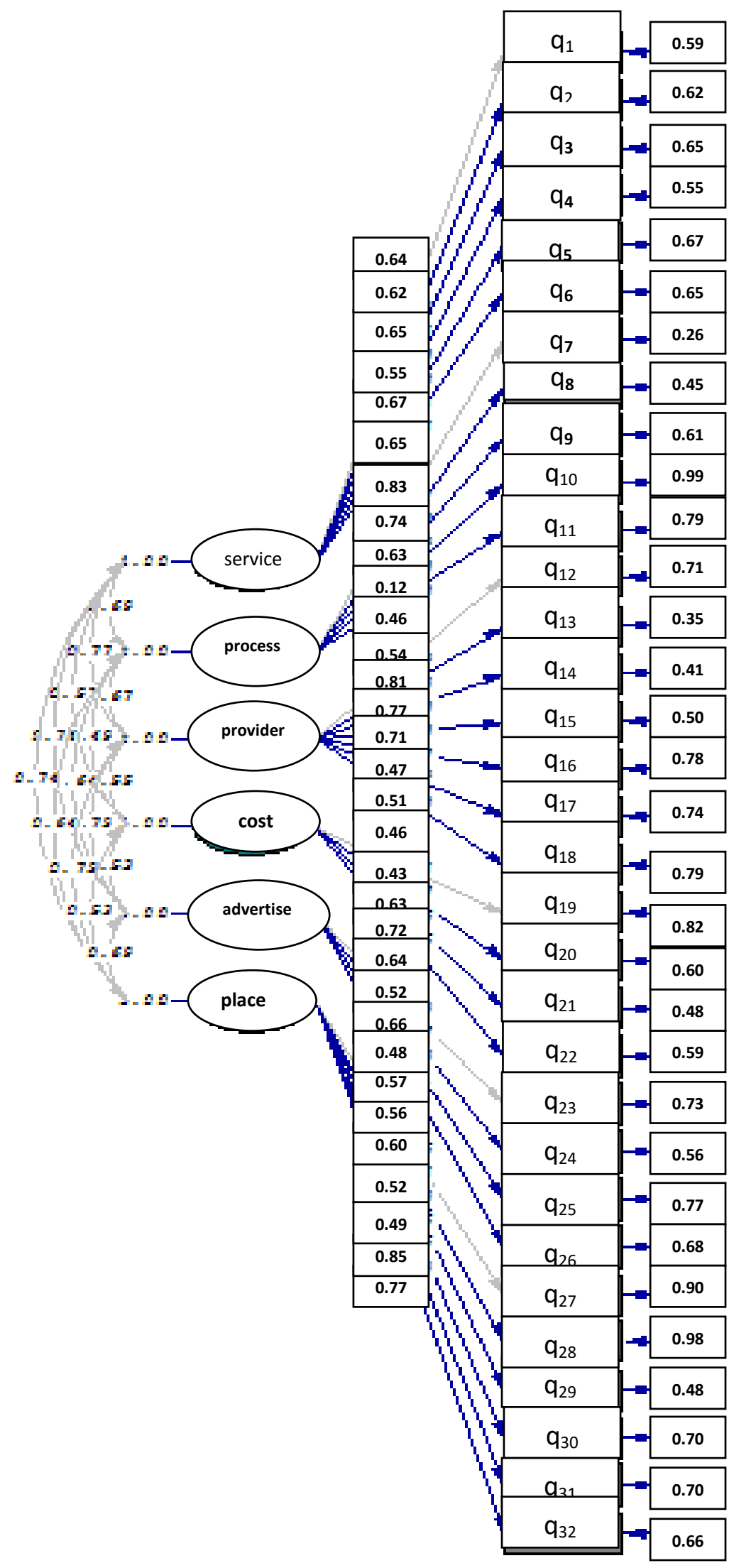

Figure 1. The final model (the effect of variables in public hospital) 
Based on the results of Jannati's research, the cost of services was more effective factor for choosing a public hospital rather than private hospitals. This is against the result of this study but the services point of view is confirmed by this study. It has been mentioned that quality is an effective factor in choosing a hospital. This factor was higher in private hospitals (average 53.15) compared to government hospitals (average 49.11) [29].

The results of Eskandari's study (2011), mentioned that the tendency of low cost is the reason of choosing a public hospitals (Arash). This result was against the result of this study [30]

According to yaghoobi's research (2010), all of the indexes were against the result of this study except the services point of view [31].

According to Alizadeh et al.'s study (2012), the services and providers point of view are confirmed by this study [32].

According to Bin et al.'s (2012) study, all of indexes were confirmed by this study except the cost point of view (five dimensions that influence a patient's choice of a hospital: convenient administrative procedures, quality of services, hospital image, cost of treatment, and health insurance coverage)[33].

\section{Conclusion}

It's necessary to improve the processes, expertise, equipment, quality and quantity of services based on the needs and expectations of patients. The study showed that primipara women usually don't pay attention to the service costs and the distant to hospital, and they tend to choose hospitals with high quality, quick service and trained doctors and medical staff, under the influence of people around them who have had similar experiences.

Hospitals and authorities must provide Medical facilities and welfare in hospitals and try to solve problems, and apply comprehensive planning in order to create more confidence and attract more patients.

\section{Acknowledgments}

We would like to appreciate all those who helped us in this study, especially Dr. Mohammadkarim Bahadori.

\section{Authors' Contributions}

Khalil Alimohammadzadeh conducted the study concept and design and developed the methods. Sedighe Zalzar collected the data. Khalil Alimohammadzadeh and Sedighe Zalzar analyzed and interpreted the data. All of the authors contributed to the revision of the manuscript, read, and approved the final version.

\section{Financial Disclosure}

The authors declare no financial interests related to the material in the manuscript.

\section{Funding/Support}

The authors declare no Funding/Support.

\section{References}

1. Varmrghani M, Arab M, Zeraati H, Aliakbari S. Factors affecting on the choice of public and private hospitals in Tehran for treatment in 1387. Journal of Hospital. 2011;10(1):45-52.

2. Yildırım HH, Hughes D, Yıldırım T. Markets, modernisation and national interest: three faces of patient choice policy in Turkey. Health Soc Care Comm. 2011;19(2):168-77.
3. van Empel IW, Dancet EA, Koolman XH, Nelen WL, Stolk EA, Sermeus W, et al. Physicians underestimate the importance of patient-centredness to patients: a discrete choice experiment in fertility care. Hum Reprod. 2011;26(3):584-93.

4. Shahraki Sanavi F, Navidian A, Rakhshani F, Ansari Moghadam AR The study on attitudes of pregnant women with a desire to cesarean section based on the theory of behavior planning. Hormozgan University of Medical Sciences. 2013.17(6):531-9.

5. Al-Doghaither A, Abdelrhman B, Saeed AW, Magzoub M. Factors influencing patient choice of hospitals in Riyadh, Saudi Arabia. J R Soc Promot Health. 2003;123(2):105-9.

6. Jamshidi Orak R, Haghani H, Mohaghegh B, Roostaei N. Preferences of clients Refferring to Firoozgar hospital: choice based conjoint analysis, Hakim Res J. 2012;15(3):213-220.

7. Robertson R, Burge P. The impact of patient choice of provider on equity: analysis of a patient survey. J Health Serv Res Policy. 2011;16(suppl 1):22-28.

8. Bronstein JM, Johnson VA. Patient's choice of hospital or office for Medicaid ambulatory care in Alabama. Med Care. 1996;34(4):34860.

9. Lin WB. Factors affecting hospital's adoption of a market orientation. WSEAS Transactions on Business and Economics. 2011;8(2):66-78

10. Victoor A, Delnoij DM, Friele R.D, Rademakers JJ. Determinants of patient choice of healthcare providers: a scoping review. BMC Health Serv Res. 2012;12(1):272.

11. Kalish RB, McCullough L, Gupta M, Thaler HT, Chervenak FA. Intrapartum elective cesarean delivery: a previously unrecognized clinical entity. Obstet Gynecol. 2004;103(6):1137-41.

12. Javadi M, Karimi S, Raiesi AR, Yaghoubi M, Shams A, Kadkhodaie M. Organizational justice and responsiveness in selected private and public hospitals of Isfahan, Iran. J Sch Public Health Inst Public Health Res. 2012;9(4):11-20

13. Srivoravilai NT, Melewar MJ, Liu and N. Yannopoulou, Value marketing through corporate reputation: An empirical investigation of Thai hospitals. J Mark Manage. 2011;27(3-4):243-68.

14. Azari Z. The effect of the chosen method of delivery of persuasive communication in the attitude of pregnant women referred to health centers - central areas of maternal and child health in Tehran. The School of Public Health and Health Services, Tehran University of Medical Sciences, Thesis Master of Public Health, 2013.

15. Rademakers JJ, Nijman AE, Brabers JD, de Jong, Hendrik ,M. The relative effect of health literacy and patient activation on provider choice in the Netherlands. Health Policy. 2014;114(2):200-6.

16. Berendsen, A.J., G.M. de Jong, J. Schuling, H.E. Bosveld, M.W. de Waal, G.K. Mitchell, K. van der Meer, and B. Meyboom-de Jong, Patient's need for choice and information across the interface between primary and secondary care: a survey. Patient Educ Couns 2010;79(1):100-5.

17. Moscone F, Tosetti E, Vittadini G. Social interaction in patients' hospital choice: evidence from Italy. J R Stat Soc Ser A Stat Soc. 2012;175(2):453-72.

18. Baie RR, Wysocki A, Gravenstein S, Cooper E, Mor V, Clark M. A Qualitative Study of Choosing Home Health Care After Hospitalization: The Unintended Consequences of 'Patient Choice'Requirements. J Gen Intern Med. 2015;30(5):634-40.

19. Yip WC, Wang H, Liu Y. Determinants of patient choice of medica provider: a case study in rural China. Health policy and plann. 1998;13(3):311-22.

20. Ameri H, Panahi M, Jafari AKh, KHalfi A, Alizadeh H, Abbaspoor R. Reasons for choosing private hospitals to treat patients in Yazd. Torbat Haidarieh University of Medical Sciences. 2013;1(3):37-43. Persian

21. Tavana, M., relation between services Utility with the Tendency of Patients to Public and Private Hospitals. 2012

22. Orr D, Sidiki SS, McGhee CN. Factors that influence patient choice of an excimer laser treatment center. J Cataract Refract Surg. 1998;24(3):335-40

23. Lis CG, Rodeghier M, Gupta D. The relationship between perceived service quality and patient willingness to recommend at a national oncology hospital network. BMC Health Serv Res. 2011;11(1):46.

24. Alrubaiee L, Alkaa'ida F. The mediating effect of patient satisfaction in the patients' perceptions of healthcare quality-patient trust relationship. IJMS. 2011;3(1):103-27.

25. Lux MP, Fasching P, Schrauder M, Löhberg C, Thiel F, Bani M, et al. The era of centers: the influence of establishing specialized centers on patients' choice of hospital. Arch Gynecol Obstet. 2011;283(3):559-68.

26. Gowrisankaran G, Lucarelli C, Schmidt-Dengler P, Town R. The impact of the Medicare Rural Hospital Flexibility Program on patient 
choice. Int J Ind Orgn. 2011;29(3):342-4.

27. Birk HO, Henriksen LO. Which factors decided general practitioners' choice of hospital on behalf of their patients in an area with free choice of public hospital? A questionnaire study. BMC Health Serv Res. 2012;12(1):126.

28. Khayatan M, Nasiripour AA, Amini M, Mohammadnejad SM. Factors effective access to services From the perspective of employees in urban health centers of the city Rey Health Network. Payavard Salamat. 2010.4(3):18-27.

29. Jannati, A., E. Dadgar, M. GHolizadeh, L. Alizadeh, and M.T KHodayari, Identifying the Main Factor to Choose Public or Private Hospital for Health Services in Hospitals of Tabriz in 2010. Toloo-eBehdasht. 2013;12(1):133-42. Persian
30. Eskandari N. The Study of Factors Affecting the Choice of Hospitals (Public and Private) for Operation by Women in Tehran, case study: Arash public hospital and Madaran private hospital, 2011.

31. Yaghoobi M, Aghamiri Z, Karimi S, Javadi M. Factors that influence patient preference in choosing a hospital based on factors of marketing mix of services in hospitals. Hakim Res J. 2011;14(2):10614. In Persian

32. Alizadeh A, Eftekhaari TE, Mousavi SH, Javidan GA, Orouji GA, Kheir SS, Mohammadi F, Dehbarez NT. Patient preferences for hospital quality in Bandar Abbas using a Discrete Choice Experiment: 2010-2011. Life Sci. 2012;9(4):1882-6. Persian

33. Bin SK. Factors affecting patient's choice of hospitals. Ann Saudi Med. 1997;18(5):420-4. 